\title{
Human Rhinovirus Infection Up-Regulates MMP-9 Production in Airway Epithelial Cells via NF-кB
}

\author{
Claire E. Tacon ${ }^{1,2}$, Shahina Wiehler ${ }^{2}$, Neil S. Holden ${ }^{3}$, Robert Newton ${ }^{3}$, David Proud ${ }^{2}$, and Richard Leigh ${ }^{1,2}$ \\ ${ }^{1}$ Department of Medicine, ${ }^{2}$ Department of Physiology and Pharmacology, and ${ }^{3}$ Department of Anatomy and Cell Biology, Airway Inflammation \\ Research Group, Snyder Institute of Infection, Immunity, and Inflammation, University of Calgary, Calgary, Alberta, Canada
}

\begin{abstract}
Human rhinovirus (HRV) infections up-regulate proinflammatory mediators and growth factors that are associated with exacerbations of inflammatory airway diseases, such as asthma and chronic obstructive pulmonary disease (COPD). Matrix metalloproteinase (MMP)-9 was shown to be increased in the airways of patients with asthma and COPD. We sought to determine whether HRV infection modulated the expression of MMP-9 and its highest-affinity inhibitor, the tissue inhibitor of metalloproteinase (TIMP)-1, and we explored the mechanism by which this modulation occurs. In vitro studies, using RT-PCR, ELISA, zymography, and a fluorescent activity assay, demonstrated that MMP-9 mRNA, protein, and activity were increased upon infection with HRV, whereas TIMP-1 mRNA and protein remained unchanged. These results were verified in vivo, using nasal lavage samples obtained from subjects with confirmed rhinovirus infections. Human rhinovirus infections were shown to up-regulate NF- $\kappa B$, and NF- $\kappa B$ has also been reported to play a role in the expression of MMP-9. We therefore investigated the role of NF- $\kappa B$ in HRV-induced MMP-9 expression. Using two inhibitors of $1 \kappa B \alpha$ kinase $\beta$, we observed a concentration-dependent decrease in HRVinduced MMP-9 expression. The role of NF-KB in HRV-induced MMP-9 expression was further confirmed using MMP-9 promoter luciferase constructs, which demonstrated that an NF-кB site at $-620 /-607$ base pairs was necessary for HRV-induced MMP-9 expression. Electrophoretic mobility shift assays and supershift assays confirmed the nuclear translocation and binding of p50/p65 NF-кB subunits to an MMP-9-specific NF- $\kappa$ B oligonucleotide. This increase in MMP-9 may be a mechanism by which rhinovirus infections contribute to airway inflammation and, potentially, to airway remodeling.
\end{abstract}

Keywords: airway epithelial cell; airway inflammation; airway remodeling; human rhinovirus; matrix metalloproteinase- 9

Human rhinovirus (HRV) infections are associated with exacerbations of lower airway diseases, such as asthma and chronic obstructive pulmonary disease (COPD) (1). More than 100 serotypes of HRV exist, and they may be grouped according to the cell surface receptor used to gain entry into airway epithelial cells, which are their primary site of infection $(2,3)$. More than

\section{(Received in original form June 18, 2009 and in final form August 27, 2009)}

This study was supported by an establishment grant from the Alberta Heritage Foundation for Medical Research (AHFMR), and by operating grants from the Canadian Institutes of Health Research (CIHR) and the Alberta Lung Association (ALA). C.E.T. received an ALA Studentship. N.S.H. is supported by an Izaak Walton Killam Post-Doctoral Fellowship. R.N. is a CIHR New Investigator and AHFMR Scholar. D.P. holds a Canada Research Chair in Inflammatory Airway Diseases. R.L. is a CIHR Clinician-Scientist (Phase 2) and an AHFMR Clinician Investigator, and holds the GlaxoSmithKline-CIHR Professorship in Inflammatory Lung Disease.

Correspondence and requests for reprints should be addressed to Richard Leigh, M.B.Ch.B., Ph.D., Health Research Innovation Centre, 3280 Hospital Drive NW, Room 4C62, Calgary, AB, T2N 4Z6 Canada. E-mail: rleigh@ucalgary.ca

This article contains an online supplement, which is accessible from this issue's table of contents at www.atsjournals.org

Am J Respir Cell Mol Biol Vol 43. pp 201-209, 2010

Originally Published in Press as DOI: 10.1165/rcmb.2009-02160C on September 25, 2009

Internet address: www.atsjournals.org

\section{CLINICAL RELEVANCE}

The mechanisms by which rhinovirus infections cause exacerbations of asthma and chronic obstructive pulmonary disease remain to be fully characterized. We describe, both in vitro and in vivo, how rhinovirus infection of airway epithelial cells upregulates the production of matrix metalloproteinase-9. These data offer insights into the molecular mechanisms by which rhinovirus infections result in asthma exacerbations and, possibly, airway remodeling.

$90 \%$ of these HRV serotypes belong to the major group that attaches to the host cell via intercellular adhesion molecule-1, whereas at least 10 serotypes belong to the minor group and use members of the low-density lipoprotein receptor family for attachment (4).

Although HRV infections are strongly linked to exacerbations of asthma and COPD, the mechanisms by which such infections cause these exacerbations are not yet fully characterized. It was demonstrated that the HRV infection of airway epithelial cells in vitro induces the production of various cytokines, chemokines, growth factors, and host defense proteins, several of which are also detected in airway secretions during in vivo HRV infections $(5,6)$. According to the current paradigm, these cellular products serve as chemoattractants and activators for the inflammatory cells that are recruited to the airways during disease exacerbations.

Matrix metalloproteinases (MMPs) are a family of 24 proteolytic enzymes that play an important role in inflammatory cell recruitment by contributing to the disruption of extracellular matrix and cellular junctions. They can also regulate the availability, activation, and inactivation of numerous proteins, including growth factors, cytokines, and chemokines. Matrix metalloproteinase-9 is the largest and most structurally complex member of the MMPs (7). The high-affinity, endogenous inhibitor of MMP-9, the tissue inhibitor of matrix metalloproteinase (TIMP)-1, forms a stoichiometric 1:1 complex with MMP-9, and the balance between TIMP-1 and MMP-9 expression plays an important role in regulating MMP-9 activity within tissues.

The expression of MMP-9 is increased in the sputum of patients experiencing an exacerbation of COPD, and in the lavage samples of patients experiencing asthma exacerbations $(8,9)$. Given that HRV infections are causally associated with exacerbations of COPD and asthma, we hypothesized that HRV infection may also alter the epithelial expression of MMP-9. Here we provide the first demonstration that HRV infection of human bronchial epithelial (HBE) cells in vitro increases the expression of MMP-9, but not of TIMP-1, and that this HRV-induced production of MMP-9 occurs via an NF-кBdependent mechanism. We further extend these studies to demonstrate that levels of MMP-9, but not of TIMP-1, are increased in nasal secretions from otherwise healthy individuals with confirmed, naturally acquired HRV infections. These 
results suggest that MMP-9 may contribute to the pathogenesis of HRV-induced exacerbations of COPD and asthma. Part of this work was published in abstract form $(10,11)$.

\section{MATERIALS AND METHODS}

\section{Materials}

Reagents were obtained from suppliers as indicated: Ham's F-12 medium, Eagle's minimal essential medium, Hanks' balanced salt solution, penicillin-streptomycin-amphotericin B, L-glutamine, TRIzol reagent, sodium pyruvate, nonessential amino acids, gentamicin, FBS (Invitrogen Life Technologies, Burlington, ON, Canada), bronchial epithelial cell growth medium (BEGM; BioWhittaker, Walkersville, MD), TaqMan master mix, $20 \times$ glyceraldehyde-3-phosphate dehydrogenase (GAPDH), RNase inhibitor and reverse transcriptase (Applied Biosystems, Foster City, CA), MMP-9 and TIMP-1 ELISAs (matched antibody pairs), MMP-9 fluorogenic activity assay (R\&D Systems, Minneapolis, MN), PS-1145, ML120B (Millennium Pharmaceuticals, Cambridge, MA), TransIT (Mirus, Madison, WI), pGL4.10[luc2] vector (Promega, Madison, WI), Firefly luciferase assay kit (Biotium, Inc., Hayward, CA), and antibodies used in supershift experiments for p50 (sc-114), p65 (sc-109), c-Rel (sc-70), and p52 (sc-848) (Santa Cruz Biotechnology, Santa Cruz, CA). All other chemicals were purchased from Sigma-Aldrich (St. Louis, MO).

\section{In Vitro Virus Preparation}

The HRV major serotype 16 (HRV-16) and minor serotype 1A (HRV1A) were propagated in WI-38 fibroblasts and H1-HeLa cells (American Type Culture Collection, Rockville, MD), respectively, and purified via centrifugation on a sucrose cushion, as described previously (12). Viral titers were determined using WI-38 or H1-HeLa cells grown in 96-well plates, as described previously (13). Replication-deficient HRV-16 and HRV-1A were produced by exposure of aliquots of the purified viral stock to a Spectroline model XX-15F high-intensity, short-wavelength $(254 \mathrm{~nm})$ ultraviolet (UV) lamp, at a distance of $5 \mathrm{~cm}$ for 7 minutes. Inactivation was confirmed by the inability of stocks to replicate and cause cytopathic effects in WI-38 or H1-HeLa cells, respectively.

\section{Culture and Viral Infection of Bronchial Epithelial Cells}

Primary human bronchial epithelial (HBE) cells were obtained by the protease digestion of nontransplanted normal human lung tissue (14), and the BEAS-2B cell line was a gift from Dr. Curtis Harris (National Cancer Institute, Bethesda, MD). These cells were cultured on 6-well culture plates (Corning, Inc., Corning, NY) in serum-free BEGM. Cells were pretreated for 4 hours in bronchial epithelial basal media (BEBM) before stimulation with virus, and this basal medium was used in all experimental procedures. Subconfluent (70-80\%) HBE cell monolayers were washed with HBSS and exposed to HRV-16 or HRV1A. Primary cells were infected with a $10^{5.5} 50 \%$ tissue cultureinfective dose $\left(\mathrm{TCID}_{50}\right) \mathrm{U} / \mathrm{ml}$ (multiplicity of infection [MOI], 1.0), whereas BEAS-2B cells were infected with $10^{4.5} \mathrm{TCID}_{50} \mathrm{U} / \mathrm{ml}$ (MOI, $\sim 0.1)$. The higher dose used in primary cells is necessary to ensure robust responses, because even at high doses of HRV, no more than $10 \%$ of HBE cells are infected (15). Cells were incubated at $34^{\circ} \mathrm{C}$ for the times indicated, at which point supernatants and total cellular RNA were harvested (using TRIzol reagent) and stored at $-80^{\circ} \mathrm{C}$ for later analysis. Each " $n$ " represents an individual primary donor or individual BEAS-2B passage.

\section{Real-Time RT-PCR}

The expression of MMP-9 and TIMP-1 mRNA was quantified using an Applied Biosystems Model 7900 Sequence Detector. The treatment of samples with DNase I (Ambion, Austin, TX) ensured minimal genomic contamination. Input RNA (400 ng) was reverse-transcribed into cDNA, followed by PCR amplification in the presence of specific forward and reverse primers (University of Calgary DNA Services, Calgary, AB, Canada) and probes (Applied Biosystems). Primers and probe for MMP-9 included forward primer 5'-GCCTTTGGACACG CACG-3', reverse primer 5'-AGCGGTCCTGGCAGAAATAG-3', and probe (spanning the junction of exons 12 and 13) $5^{\prime}$-FAMTTCCAGTACCGAGAGAAA-3'. Primers and probe for TIMP-1 included forward primer 5'-GACGGCCTTCTGCAATTCC-3', reverse primer 5'-TCTGGTGTCCCCACGAACTT-3', and probe (spanning exons 1 and 2) 5'-FAM-CCTCGTCATCAGGGC-3'. Analysis of the housekeeping gene $G A P D H$ was performed on each sample, using a primer and probe kit obtained from Applied Biosystems (catalogue number 4326317E). Both MMP-9 and TIMP-1 mRNA concentrations were calculated using the comparative $\mathrm{C}_{\mathrm{T}}$ method, as previously described (16), and are expressed relative to GAPDH.

\section{ELISAs and MMP-9 Fluorogenic Assay}

We performed ELISA assays for MMP-9 and TIMP-1 protein, using matched antibody pairs according to the manufacturer's protocol (R\&D Systems, Minneapolis, MN), with recombinant MMP-9 and TIMP-1 used as standards. The sensitivities of the assays were $23 \mathrm{pg} / \mathrm{ml}$ for MMP-9, and $31 \mathrm{pg} / \mathrm{ml}$ for TIMP-1. The active MMP-9 fluorescence assay was performed according to the manufacturer's protocol (R\&D Systems), and consisted of applying cellular supernatants onto a plate precoated with an antibody directed to human MMP-9 (both propeptidecontaining and active forms). After washing to remove unbound substances, a fluorogenic substrate molecule linked to a quencher was added. Active MMP-9 cleaves the link between the quencher and fluorescent molecule, resulting in a fluorescent signal. Interpolation of a standard curve (recombinant MMP-9 activated with 4-p-aminophenyl mercuric acetate [APMA]) allows for the quantification of MMP-9 activity.

\section{Gelatin Zymography}

The standardization of protein loaded onto each gel was performed using a detergent-compatible protein assay (Bio-Rad, Montreal, PQ, Canada). Nonreducing Laemmle's buffer was added to the supernatants, and proteins were immediately separated on $7.5 \%$ SDS-PAGE gels containing $1 \mathrm{mg} / \mathrm{ml}$ gelatin. After electrophoresis, gels were washed in rinse buffer $\left(50 \mathrm{mM}\right.$ Tris- $\mathrm{HCl}, 10 \mathrm{mM} \mathrm{CaCl}, 1 \mathrm{M} \mathrm{ZnCl}_{2}$, and $2.5 \%$ Triton $\mathrm{X}-100$ ) for 15 minutes, and incubated overnight in fresh rinse buffer. Gels were subsequently rinsed with distilled water and incubated in reaction buffer $\left(50 \mathrm{mM}\right.$ Tris- $\mathrm{HCl}, 10 \mathrm{mM} \mathrm{CaCl}_{2}$, and 1 $\mathrm{M} \mathrm{ZnCl}_{2}$ ) for 24 hours at $37^{\circ} \mathrm{C}$. Gels were stained with Coomassie blue $\mathrm{R}-250(2.5 \mathrm{mg} / \mathrm{ml}$ in $30 \%$ isopropanol and $10 \%$ acetic acid) for 1 hour and then destained in 10\% isopropanol and $10 \%$ acetic acid until clear bands were visible. The activity of MMP-9 was identified as clear bands where the gelatin had been degraded. A Fluor-S MAX MultiImager (Bio-Rad Laboratories, Hercules, CA) was used to capture images of the gels. Positive controls were generated by exposing MMP-9-rich supernatant from TNF- $\alpha(10 \mathrm{ng} / \mathrm{ml})$-activated neutrophils to APMA $(1 \mathrm{mM})$ at $37^{\circ} \mathrm{C}$ for 2 to 4 hours.

\section{Luciferase Promoter Constructs}

A 1,717-base pair (bp) MMP-9 promoter construct, corresponding to the sequence from -1723 to -6 relative to the transcription start site of the $5^{\prime}$-flanking region of the human MMP-9 gene, was generated from human genomic DNA, using specifically designed forward $5^{\prime}$-CAT GGTACCATGCTCATGCCCGTAATCC-3' and reverse 5'-CATGC TAGCGGCAGAGGTGTCTGACTGC- $3^{\prime}$ primers incorporating K $\overline{p n 1}$ and Nhe1 restriction sites (underlined) at the $5^{\prime}$ ends and $3^{\prime}$ ends, respectively. The amplicon was then inserted upstream of the luciferase reporter gene in the pGL4.10[luc2] vector (Promega). Putative transcription factor-binding sites were identified using Genomatix MatInspector program analyses and precedents from the literature (17-19). The various truncations were generated using custom-designed primers, again incorporating the relevant restriction enzyme sites (underlined) to allow for proper orientation upstream of the luciferase reporter, 1,017-bp construct forward 5'-CATGGTACCTCTGGGCTCAAGCAATCC-3', the 940-bp construct $5^{\prime}$-CATGGTACCCCATACCTGGCCCTGAA TCT-3', the 681-bp construct 5'-CATGGTACCTGCTACTGTCCCCT TTACTGC- $3^{\prime}$, the 604-bp construct $\overline{5}^{\prime}$-CATGGTACCTGCCTAGCA GAGCCCATT-3', the 553-bp construct 5'-CATGGTACCCTGAGT CAAAGAAGGCTGT- $3^{\prime}$, and the 324-bp construct $5^{\prime}$-CATGGTACC CССТСССТСССТTCATACA-3'. All constructs were sequenced and confirmed to be identical to those reported for the MMP-9 promoter on chromosome 20. Point mutations within the various transcription factor-binding sites were performed, using standard site-directed mutagenesis methodologies within the 1,017-bp construct. Forward primer sequences, with lowercase letters to indicate mutated residues, 
comprised the mutated interferon regulatory factor-4 (mIRF4), 5' TGCTGTTgTCTAtAGGCTGCT-3'; mNF-кB-1, 5'-AGACAGGGtGT TGCaCCAGT-3'; mNF-кB-2, 5'-GTtGAATTaCCCAGCCTTGC-3'; mNF-кB-1,2, 5'-GtGTTGCaCCAGTtGAATTaCCCAGCC-3'; and mNF-кB-3， 5'-GGGtGATCCaTCCAGCTTCATCC-3'. All construct sequences were confirmed using DNA sequencing.

\section{Promoter Construct Transfection and Luciferase Assay}

Each MMP-9 promoter construct $(0.2 \mu \mathrm{g} / \mathrm{ml})$ was transiently transfected into subconfluent (30-40\%) monolayers of BEAS-2B cells for 5 hours in basal medium using TransIT (Mirus). Cells were then allowed to recover overnight in BEGM containing 5\% FBS. The next day, cells were infected with HRV-16, as already described. At 48 hours after HRV infection, cells were lysed in luciferase lysis buffer (Promega), followed by scraping, freezing, and centrifugation. Firefly luciferase activity was measured using a luciferase reporter assay system. Six separate experiments $(n=6)$ were performed, and the results of each experiment were averaged from triplicate wells.

\section{Electrophoretic Mobility Shift Assay and Supershift Assays}

Primary and BEAS-2B cells were infected with HRV as already described. At the appropriate time, nuclear extracts were isolated, as previously described (20). Double-stranded oligonucleotides containing the NF-кB-1,2 recognition site from the MMP-9 promoter were labeled with T4 polynucleotide kinase (New England Biolabs, Pickering, ON, Canada) and [ $\gamma$-32P]ATP (PerkinElmer, Boston, MA). For binding reactions, $2.5 \mu \mathrm{g}$ of nuclear extracts were incubated with $4 \mu \mathrm{l}$ of binding buffer ( $20 \%$ glycerol, $5 \mathrm{mM} \mathrm{MgCl} 2,2.5 \mathrm{mM}$ EDTA, $1 \mu \mathrm{g}$ of poly(dI:dC), $250 \mathrm{mM} \mathrm{NaCl}, 50 \mathrm{mM}$ Tris- $\mathrm{HCl}$, and $0.01 \mathrm{M}$ DTT). Buffer D (0.02 M Hepes, $\mathrm{pH} 7.9,20 \%$ glycerol, $0.05 \mathrm{M} \mathrm{KCl}, 0.2 \mathrm{mM}$ EDTA, $\mathrm{pH}$ 8.0, 0.5 mM PMSF, and 0.01 M DTT) was used to bring the mixture to $14 \mu \mathrm{l}$. Samples were incubated for $20 \mathrm{~min}$, labeled probe was added, and samples were further incubated for 1 hour on ice. For supershift assays, samples were incubated with the appropriate antibody for 2 hours before the addition of the labeled probe. Samples were fractionated on $6 \%$ acrylamide gels, before vacuum drying and autoradiography. The forward oligonucleotide sequence was 5'-GAAGACAGG GGGTTGCCCCAGTGGAATTCCCCAGCCTTGC-3'.

\section{Clinical Study Design and Methods}

We performed a prospective, cross-sectional study in which otherwise healthy, nonsmoking, nonallergic subjects were invited, through local advertizing, to report to the research clinic within 36 hours after the onset of cold symptoms. Subjects completed a validated symptom questionnaire (16) and underwent nasal lavage, as described previously (6). Symptom scores and nasal lavage were repeated on the 2 subsequent days. After the resolution of cold symptoms, 4 weeks after the third visit, subjects returned to the clinic for a retrospective baseline visit (visit 4), at which time symptom scores and nasal lavage were repeated. We also recruited healthy, nonsmoking control subjects without cold symptoms, whose outcomes were measured during a single visit. All subjects provided written, informed consent, and the protocol was approved by the Conjoint Health Ethics Board of the Faculties of Medicine, Nursing, and Kinesiology, University of Calgary.

Nasal lavage samples were centrifuged at 2,500 $\times g$ for 5 minutes at $4^{\circ} \mathrm{C}$, and BSA was added to supernatants at a final concentration of $0.5 \%$. Lavage supernatant samples were then aliquoted and stored at $-80^{\circ} \mathrm{C}$ for later analysis. Viral RNA from nasal lavage samples was isolated using the QIAamp Viral RNA Mini Kit (Qiagen, Mississauga, ON, Canada), as described previously (6). The RNA was reversetranscribed using oligo(dT) and Superscript II (Invitrogen Life Technologies, Burlington, ON, Canada). Nasal lavage supernatants from all study participants were screened for HRV, using a quantitative, realtime RT-PCR technique. To enable the quantification of detected HRV genomic material in nasal lavages, test samples were compared against a standard curve that was analyzed in parallel in each assay, as described previously (6). We also previously established that viral titers quantified using RT-PCR correlate highly with values obtained using standard cell-based viral titer assays (21). Samples were obtained from nine subjects (mean age, $40 \mathrm{yr}$; range, 21-59 yr; 6 women) with established HRV infections. Samples obtained from the same subjects 4 weeks later, when they had been symptom-free for more than 2 weeks, were confirmed to be negative for HRV by real-time RT-PCR. Samples were obtained from 11 asymptomatic control subjects (mean age, $28 \mathrm{yr}$; range, 22-52 yr; 6 women) who were confirmed to be negative for HRV by real-time RT-PCR.

\section{Statistical Analysis}

All data were normally distributed, and the reported values are expressed as means and standard errors of the mean (SEMs). Between-group comparisons were made using one-way ANOVA, with Newman-Keuls post hoc multiple-comparison testing to assess significant effects. Descriptive statistics were used to summarize the baseline characteristics of study subjects in the clinical study. Correlations between continuous variables were assessed using Pearson's correlation coefficient. All comparisons were two-tailed, and $P<0.05$ was considered significant.

\section{RESULTS}

\section{HRV Infection of HBE Cells Up-Regulates Production of MMP-9 but Not TIMP-1}

Initially we evaluated whether the HRV infection of HBE cells resulted in any changes in MMP-9 or TIMP-1 expression. Timecourse studies showed that infection with intact HRV-16 and HRV-1A virus, but not UV-treated, replication-deficient HRV16 or HRV-1A in primary HBE cells (Figures $1 \mathrm{~A}$ and $1 \mathrm{~B}$, and Figures E1A and E1B in the online supplement), and in the BEAS-2B cell line (Figures E2A and E2B), resulted in a timedependent increase in the expression profiles of MMP-9 mRNA and supernatant protein $(P<0.02)$. Furthermore, the infection of $\mathrm{HBE}$ cells with varying dilutions of HRV-16 for 24 hours indicated that this $\mathrm{HRV}$-induced increase in MMP-9 protein expression occurred in a concentration-dependent manner $(P=$ 0.003) (Figure E3). The MMP-9 expressed by HBE cells, as well as that increased upon HRV infection, occurred only in the 92$\mathrm{kD}$ pro-form, as demonstrated by gelatin zymography (Figure 2). In addition, MMP-2 (pro-form, $72 \mathrm{kD}$ ), another gelatinase in the MMP family, was constitutively expressed, but not increased upon HRV infection (Figure 2), indicating that HRV selectively increases MMP-9 but not MMP-2. The infection of primary HBE cells with intact or UV-inactivated HRV-16 (Figures 1C and 1D) or HRV-1A (Figures E4A and E4B) did not result in the enhanced production of TIMP-1 mRNA or protein at any time. However, the basal expression of TIMP-1 protein, but not mRNA, increased with time, implying a time-dependent but HRV-independent, posttranscriptional control of this protein. The observation that only intact HRV-16 or HRV-1A increased MMP-9 mRNA and protein suggests that initial receptor signaling, as can occur upon the binding of UV-treated HRV16 to ICAM-1 $(22,23)$, is not sufficient for the observed increase in MMP-9 expression. Viral replication appears to be essential.

Although zymography allows for the identification of various forms of MMP-9, it does not determine the native activity of MMP-9. Because the pro-domain containing the 92-kD form of MMP-9 may be active (24), we performed an activity assay (specific to MMP-9) to determine the native activity of MMP-9 in cell supernatants. The infection of HBE cells with both intact HRV-16 and HRV-1A in vitro significantly increased the activity of MMP-9 in cellular supernatants $(n=7, P=0.02)$ (Figures $3 \mathrm{~A}$ and $3 \mathrm{~B}$, respectively). Therefore, infection with HRV not only results in an increased expression of MMP-9, but also increases its activity.

\section{HRV-Induced MMP-9 Expression Is Dependent on the Canonical NF-кB Pathway}

Nuclear factor- $\kappa \mathrm{B}$ is well-recognized for its role in the induction of inflammatory genes, and was shown to be activated in 

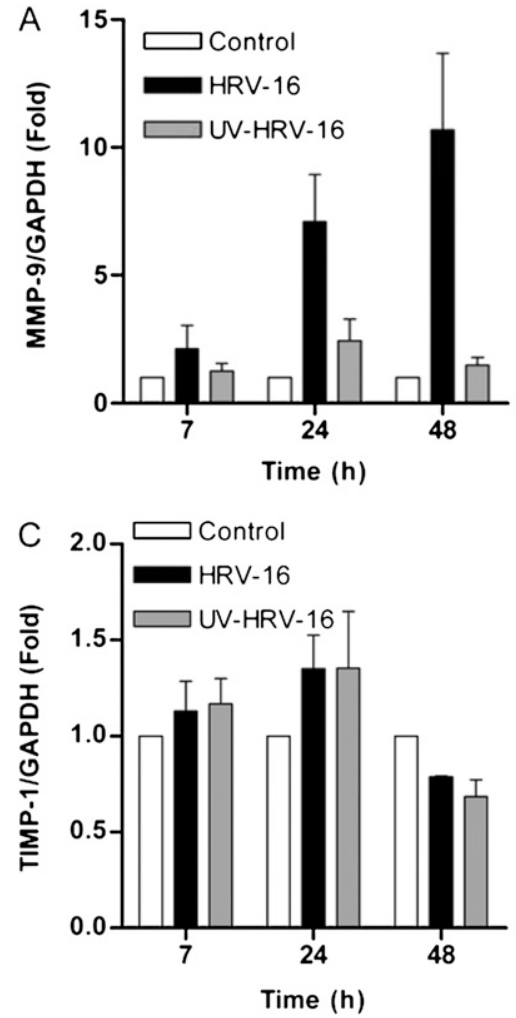
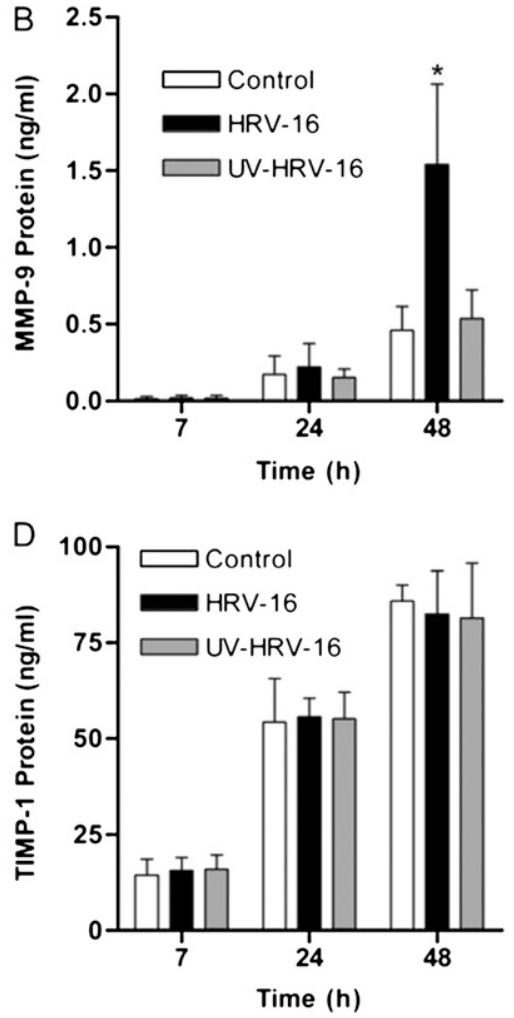

Figure 1. Time-dependent expression of MMP-9 $(A)$ and TIMP-1 (C) mRNA (fold increase relative to control at respective time point), and MMP-9 $(\mathrm{ng} / \mathrm{ml})(P<0.02)(B)$ and TIMP-1 $(\mathrm{ng} / \mathrm{ml})(D)$ protein upon HRV-16 infection of primary HBE cells. Data represent mean $\pm \operatorname{SEM}(n=3-4)$. Asterisk indicates significant differences $(P<0.05)$. response to HRV infection (25). The expression of MMP-9 was reported to be dependent on $\mathrm{NF}-\kappa \mathrm{B}$, as well as on other transcription factors (26). We therefore sought to determine whether HRV-induced MMP-9 expression was dependent on $\mathrm{NF}-\kappa \mathrm{B}$.

The expression of HRV-induced MMP-9 in both primary HBE and BEAS-2B cells (Figures 4A and 4B, respectively) was significantly decreased in a concentration-dependent manner upon the addition of a small-molecule Iк $\mathrm{B} \alpha$ kinase $\beta$ (IKK $\beta$ ) inhibitor, PS-1145 $(10-0.3 \mu \mathrm{M})(n=4, P<0.02)$. At a concentration of $10 \mu \mathrm{M}$, PS-1145 does not significantly inhibit the other IKK family members, i.e., IKK $\alpha$, TNF-receptor associated factor (TRAF) family member-associated NF- $\mathrm{KB}$ activator protein (TANK)-binding kinase 1 , and IKKE (27), but was shown to prevent the activation of $\mathrm{NF}-\kappa \mathrm{B}$ by preventing the phosphorylation and degradation of $\operatorname{I} \kappa \mathrm{B} \alpha(27,28)$. Because of concerns regarding the lack of specificity and potential offtarget effects when using a single pharmacologic inhibitor, we used a second structurally unrelated IKK $\beta$ inhibitor, ML120B.

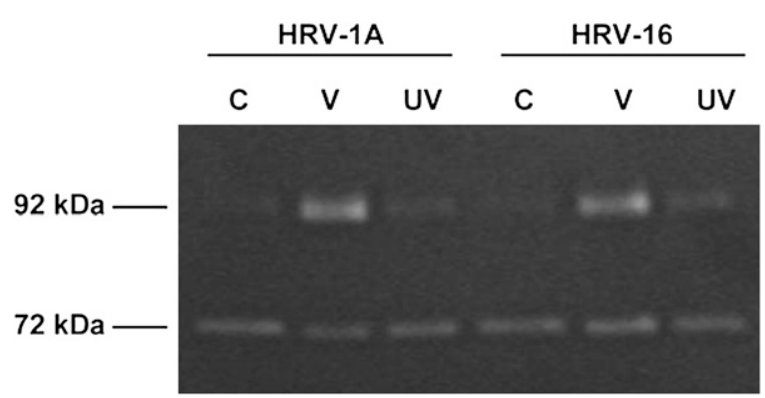

Figure 2. Zymography of supernatants of control (C) cells, or cells infected with HRV ( $V$; HRV-1A or HRV-16) or UV-inactivated HRV-1A or HRV-16 (UV), after 48 hours. Bands at 92 kD are pro-MMP-9, and at 72 $\mathrm{kD}$ are pro-MMP-2. Figure is representative of $n=3$.
The inhibitor ML120B $(10 \mu \mathrm{M})(n=4, P<0.05)$ significantly inhibited HRV-induced MMP-9 protein expression (Figure E5), thereby verifying the results obtained with PS-1145. Based on these data, we concluded that the induction of MMP-9 expression by HRV is dependent on IKK $\beta$, and likely involves the canonical NF-кB pathway.

\section{Promoter Luciferase Constructs Further Highlight a Role for NF-KB in HRV-Induced MMP-9 Expression}

To evaluate further the various transcriptional regulators that may play a role in HRV-induced MMP-9 expression, a series of MMP-9 promoter constructs was generated in the luciferase reporter plasmid, pGL4.10[luc2] vector (Figure 5). The transient transfection analysis of BEAS-2B cells revealed that the $\mathrm{HRV}$-induced reporter drive was $4.26 \pm 0.26$ for the $-1,723 /-6 \mathrm{bp}$ construct. Because the constructs $-1,017 /-6 \mathrm{bp},-940 /-6 \mathrm{bp}$, and $-681 /-6 \mathrm{bp}$ all produced a similar level of inducibility in response to HRV, we concluded that the DNA region between
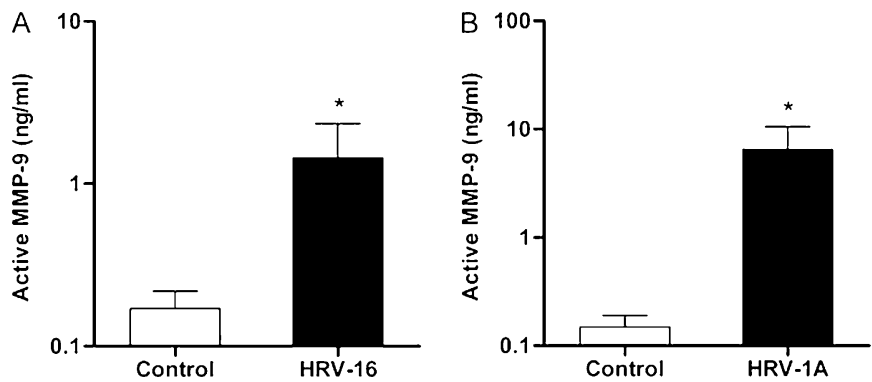

Figure 3. Activity of MMP-9 is increased upon HRV infection in vitro. Active MMP-9 $(\mathrm{ng} / \mathrm{ml})$ was measured in supernatant of noninfected control cells and in cells infected with HRV-16 $(A)$ or HRV-1A $(B)$. C, control uninfected cells; $V, \mathrm{HRV}$-infected cells. Data represent mean \pm $\operatorname{SEM}(n=7)$. 
A

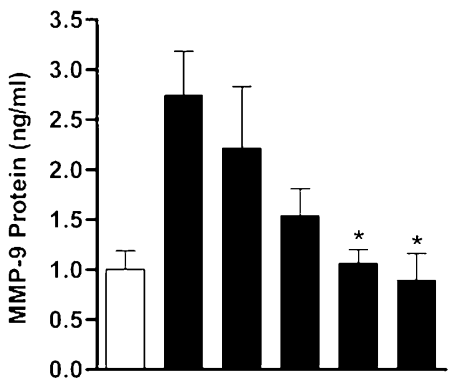

PS-1145 $(\mu \mathrm{M})$ :

HRV-16:
B

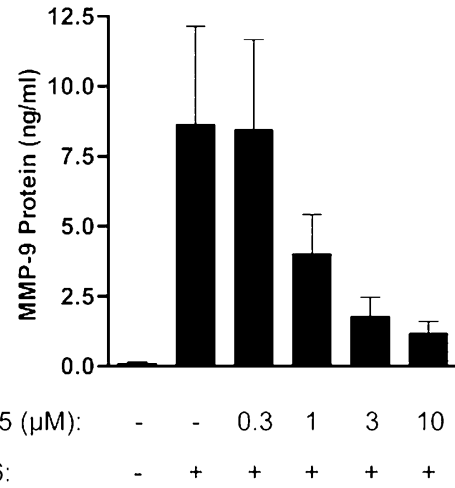

Figure 4. Dose-dependent decrease $(P<0.03)$ in HRV-induced MMP-9 protein expression $(\mathrm{ng} / \mathrm{ml})$ upon addition of IKK $\beta$ inhibitor, PS$1145(10-0.3 \mu \mathrm{M})$, in $(A)$ primary $\mathrm{HBE}$ and (B) BEAS-2B cells. Cells were pretreated with PS-1145 for $1.5 \mathrm{~h}$ before infection with HRV-16, as described in Materials and Methods. Data represent mean $\pm \operatorname{SEM}(n=4)$. Asterisks indicate significant differences $(P<0.05)$.
$-1,723$ and -681 bp upstream of the transcriptional start site is not necessary for the HRV-induced MMP-9 promoter drive (Figure 5A).

Upon further truncation of the 681-bp construct (-604/ $-6 \mathrm{bp},-553 /-6 \mathrm{bp}$, and $-324 /-6 \mathrm{bp}$ ), a loss of promoter drive was evident (Figure 5A). These data suggest that key regulatory DNA sites may lie in the interval -681 to $-604 \mathrm{bp}$. The literature (17-19) and our own Genomatix MatInspector program analysis indicate that NF- $\mathrm{B}$ sites situated at -635 /
-622 bp (NF-кB-1) and $-620 /-607$ bp (NF-кB-2) are the most readily identifiable transcription factor-binding sites within this region of the MMP-9 promoter. We therefore synthesized constructs with mutations, designed to prevent NF- $\mathrm{KB}$ binding to these sites, in either or both of the identified NF-кB binding

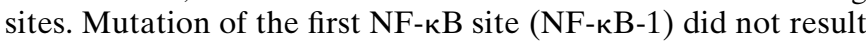
in a significant decrease in MMP-9 promoter activity upon infection with HRV. However, mutation of the second NF- $\mathrm{B}$ site, NF- $\mathrm{B}-2$, resulted in a significant abrogation of the HRV-

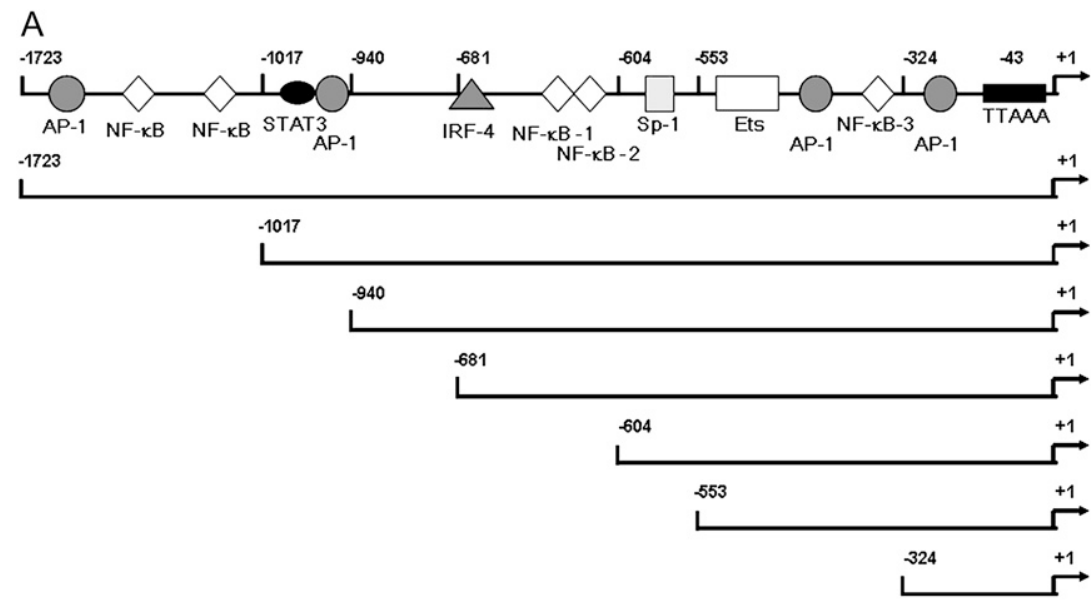

\section{Fold (Luciferase Activity)}

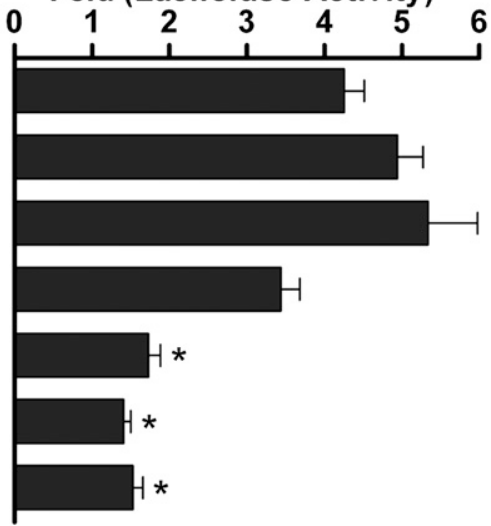

B
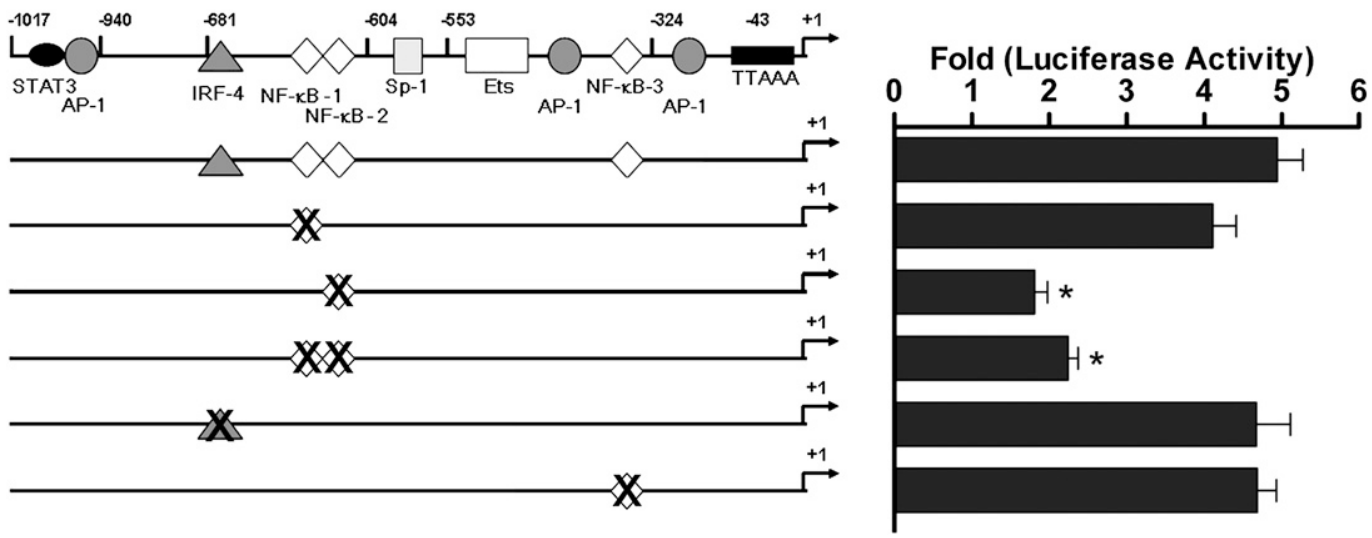

Figure 5. MMP-9 promoter-luciferase constructs. (A) HRV-induced activity of various truncations of the MMP-9 promoter (Fold (Luciferase Activity)). Data represent mean $\pm \operatorname{SEM}(n=7)$. Asterisks indicate significant inhibition $(P<0.05)$ compared with $-1,723 /-6$ bp construct. $(B)$ HRV-induced activity of various mutant MMP-9 promoter constructs (Fold (Luciferase Activity)). Data represent mean \pm SEM $(n=7)$ ). Asterisks indicate significant inhibition $(P<0.05)$ compared with $-1,017 /-6$ bp construct. Transcription factor-binding sites in MMP-9 promoter; AP-1, activator protein-1; IRF4, interferon regulatory factor 4; NF-kB, nuclear factor-kB; STAT3, signal transducer and activator of transcription-3; Sp-1, Sp-1-binding site; Ets, polyoma enhancer $\mathrm{A}$ binding protein-3. 
induced promoter drive, suggesting that the second NF- $\mathrm{B}$ site is necessary for HRV-induced MMP-9 expression. This was similar to results obtained upon mutation of both sites together $(\mathrm{mNF}-\kappa \mathrm{B}-1,2)$ (Figure $5 \mathrm{~B})$.

To confirm that the NF- $\mathrm{BB}$ site between $-553 /-6$ bp and $-324 /$ -6 bp (NF-кB-3) was not cooperating with NF-кB-1 and/or NF$\kappa \mathrm{B}-2$, it was also mutated. However, no decrease in viral drive was observed, indicating that this proximal NF- $\mathrm{BB}$ site does not play a role in HRV-induced MMP-9 expression (Figure 5B). A putative IRF4 site at $-699 /-678$ bp was also identified by MatInspector analysis. A mutation of this site, however, produced no decrease in the HRV-induced promoter drive (Figure 5B), again suggesting that this site is not necessary for HRV-induced MMP-9 expression. Other investigators reported on the importance of either one of these two $\mathrm{NF}-\kappa \mathrm{B}$ sites within this area of the human MMP-9 promoter $(17,29-31)$, and based on our data, the NF-кB-2 site is evidently necessary for HRV-induced MMP-9 expression.

\section{Electrophoretic Mobility Shift Assay Analysis of NF-кB Nuclear Localization and DNA Binding}

To confirm NF-кB nuclear localization and DNA binding, we performed an electrophoretic mobility shift assay (EMSA) and supershift assays. Using a radiolabeled oligonucleotide probe containing the sequence of NF-кB-1,2 and nuclear extracts obtained from uninfected or HRV-infected primary $\mathrm{HBE}$ and BEAS-2B cells, we initially performed time-course studies with EMSA that revealed increased binding upon infection with HRV. Binding peaked at 9-24 $\mathrm{h}$ after infection in primary cells, and at 6 to 24 hours after infection in BEAS-2B cells (Figures 6A and E6, respectively). Two specific complexes were evident in each case. To explore the composition of these two DNAbinding complexes, supershift analysis was performed, using a panel of commercially available antibodies. Supershift analysis revealed a shift in bands 1 and 2 with an antibody to p50, and a shift of band 1 using an antibody to p65, suggesting that band 1 may comprise p50/p65 heterodimers, whereas band 2 may represent p50 homodimers. Using an antibody to c-Rel, we noted the appearance of a low-intensity complex that migrated between the upper NF-кB complex and the top of the gel. However, because a corresponding reduction did not appear to occur in either of the two main NF-кB bands, we concluded that c-Rel can only represent a minor component of these DNAbinding complexes (Figure 6B).
HRV Infection In Vivo Is Associated with Increased MMP-9 Protein and Activity, but No Change in TIMP-1 Protein

To verify our in vitro data, we performed an in vivo natural cold study. Protein concentrations of MMP-9 and TIMP-1 were assessed in nasal lavage fluids from nine subjects with confirmed rhinovirus infections during the 3 days of cold symptoms, and during a 4-week retrospective baseline visit. Concentrations of MMP-9 were significantly higher during HRV infection than at baseline after clearance of the HRV infection $(P=0.007)$. In addition, the amount of MMP-9 in the lavage samples during the baseline visit was not statistically different from the amount in noninfected control subjects. Concentrations of MMP-9 also correlated with viral titers $(r=0.976$ and $P=0.005)$, indicating that HRV infection upregulates MMP-9 protein concentrations in nasal lavage samples of infected individuals (Figure 7A). However, the expression of TIMP-1 remained unchanged, at concentrations similar to those observed in asymptomatic control subjects throughout visits 1-4 (Figure 7B). In addition, the MMP-9 activity measured in nasal lavage samples, obtained during the highest viral titer visit, was increased significantly compared with the activity during the retrospective baseline visit $(n=9, P=0.01)$. Consistent with the observation that MMP-9 protein concentrations in the lavage sample during the baseline visit were similar to those in uninfected control subjects, the amount of active MMP-9 present during the baseline visit did not differ from that in lavage samples from uninfected control subjects $(n=11)$ (Figure 7C).

\section{DISCUSSION}

We provide the first demonstration that in vitro infection with major or minor HRV serotypes selectively up-regulates the airway epithelial cell production of MMP-9 mRNA, protein, and activity, without affecting concentrations of the highestaffinity inhibitor of MMP-9, TIMP-1. A similar result was obtained upon the HRV-16 infection of nasal polyp fibroblasts, when an increase in MMP-9 but not TIMP-1 expression was evident (32). Our in vivo results confirm our in vitro observations. Nasal lavage samples obtained from individuals with confirmed HRV infections demonstrated increased MMP-9 protein concentrations and activity, which subsequently decreased as viral titers declined. Concentrations of MMP-9 protein were highest at the time of peak viral titer, and declined

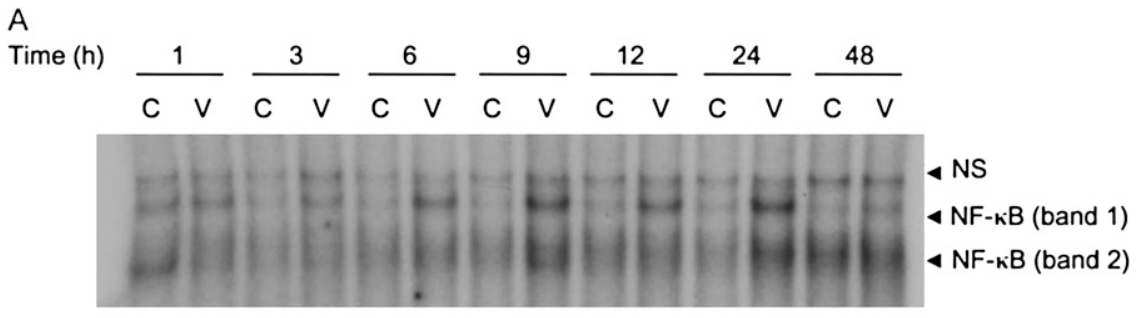

B

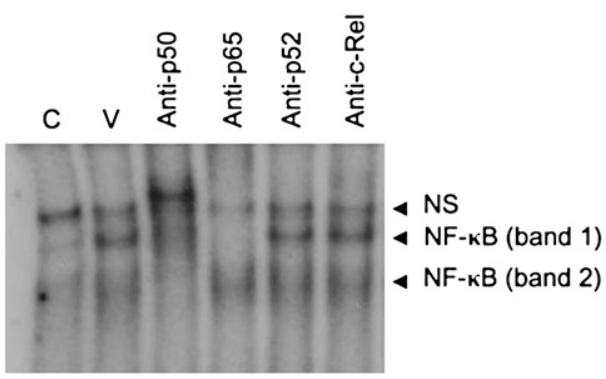

Figure 6. HRV-induced NF- $\mathrm{kB}$ nuclear translocation and DNA binding. $(A)$ HRV infection of primary HBE cells induces two bands (band 1 and 2 ) during incubation of nuclear extracts, obtained at indicated time points (1-48 $\mathrm{h}$ after infection), with $\gamma$-32P-labeled NF-kB-1,2 oligonucleotide. (B) Supershift experiments reveal p65/p50 heterodimer (band 1) and p50/p50 homodimer (band 2). C, control uninfected cells; $V$, HRV-infected cells; NS, nonspecific. Figure is representative of $n=3$. 

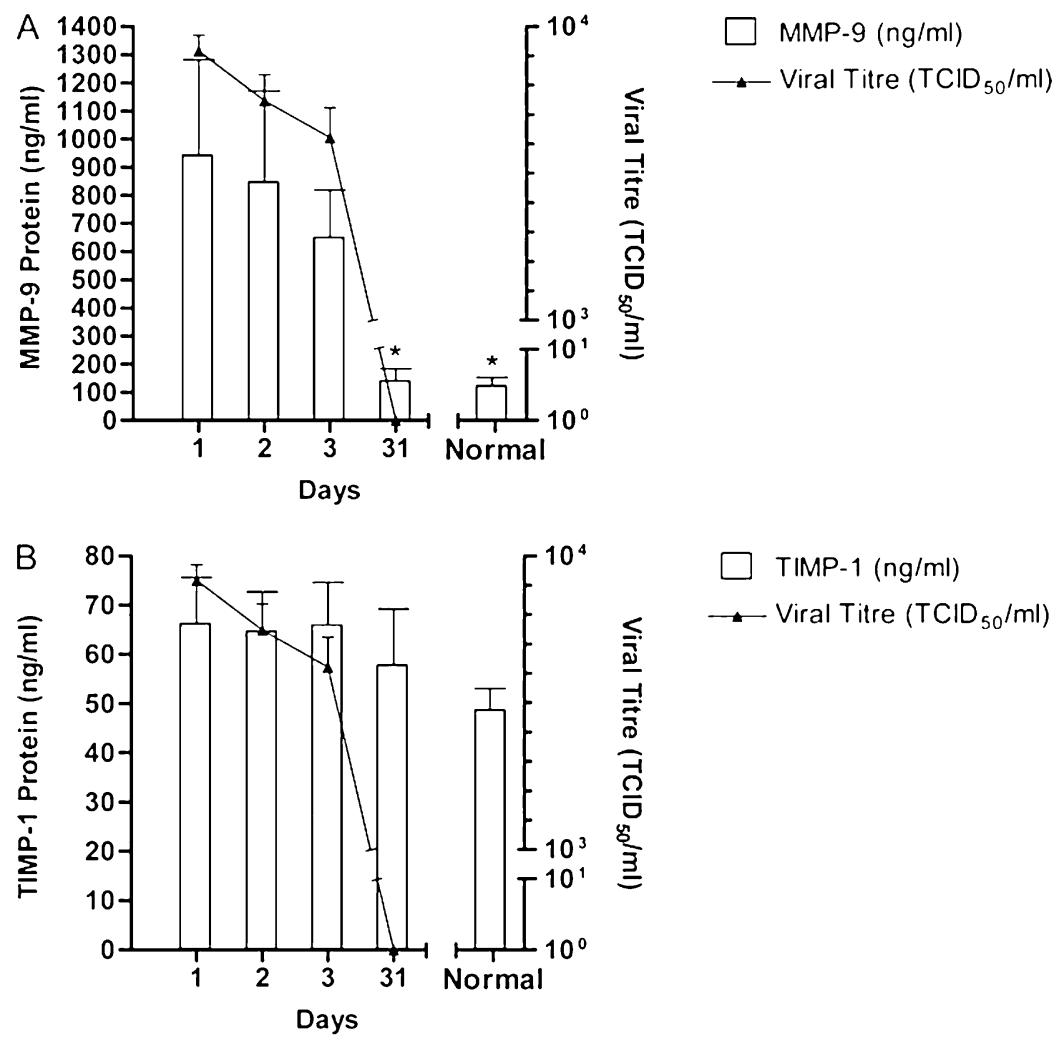

Figure 7. MMP-9 $(A)$ or TIMP-1 $(B)$ protein $(\mathrm{ng} / \mathrm{ml})$ and corresponding viral titers $\left(\mathrm{TCID}_{50} / \mathrm{ml}\right)$ in nasal lavage samples from HRV-infected individuals at time of cold symptoms (Days 1-3) and after clearance of viral infection (day 28), or in noninfected control individuals (Normal). Data represent mean \pm SEM $(n=9$ for infected individuals, $n=11$ for control subjects). (C) Active MMP-9 $(\mathrm{ng} / \mathrm{ml})$ in nasal lavage samples obtained during visit with highest viral titer (designated visit 1), during visit 4 (retrospective baseline at day 28), and in noninfected control subjects (Normal). Data represent mean \pm SEM ( $n=9$ for infected individuals, $n=11$ for control subjects). Asterisks indicate significant differences $(P<0.05)$.

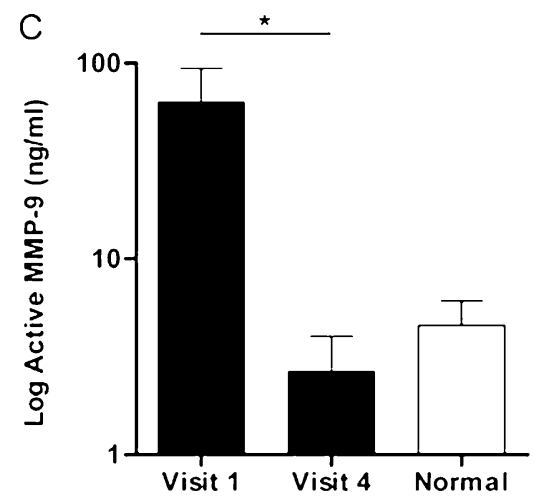

to concentrations similar to those in healthy, noninfected control subjects after confirmed clearance of the HRV infection. In contrast, concentrations of TIMP-1 were not significantly affected and remained relatively constant during acute infection and during the retrospective baseline visit.

In our studies using cultured HBEs, zymography indicated that only the $92-\mathrm{kD}$ form of MMP-9 was present. To display activity while retaining its pro-domain, disruption of the active site zinc-thiol interaction of MMP-9 would have to occur via nonproteolytic means (33). We speculate that alterations in the MMP-9/TIMP-1 molar ratio, attributable to the selective increase in MMP-9 relative to TIMP-1, contribute to the increase in MMP-9 activity. This active MMP-9 may facilitate cellular recruitment via disruption of the extracellular matrix and cell junctions, and could modulate the activity of numerous cytokines, chemokines, and growth factors, resulting in altered inflammatory profiles and cellular infiltration. However, the exact role of MMP-9 in the immunopathology of airway inflammation has not been fully characterized. Murine models of allergic airway inflammation, using MMP- $9^{-1-}$ mice or various MMP inhibitors, provided varying results regarding the in- volvement of MMP-9 in the development and resolution of airway inflammation. Such discrepancies may, at least in part, be attributed to different sensitization procedures and different genetic backgrounds of the mice (34-37). A study examining the role of MMP-9 in experimental colitis reported that epithelial cell-derived, rather than inflammatory cell-derived, MMP-9 was responsible for the tissue damage and inflammation in mice exposed to dextran-sodium sulfate or infected with Salmonella typhimurium (38).

In clinical studies, MMP-9 was shown to be increased in the airways during exacerbations in both patients with COPD and patients with asthma $(8,9)$. This increase in MMP-9 during these clinical exacerbations is thought to play an important role in the pathogenesis of airway inflammation, and may contribute to altered injury-repair cycles and to airway-remodeling processes. In support of this potential role for MMP-9 in the pathogenesis of airway remodeling, abnormalities in highresolution computed tomography scans were associated with alterations of the MMP-9/TIMP-1 ratio in patients with asthma and COPD (39). In addition, a recent in vitro study indicated a role for epithelial-derived MMP-9 in smooth muscle proliferation 
(40). Therefore, the increase of MMP-9 protein and activity upon HRV infection is likely to modulate both airway inflammation and airway-remodeling processes.

Using small-molecule IKK $\beta$ inhibitors, promoter constructs, EMSA, and supershift assays, we established that the canonical NF- $\mathrm{B}$ pathway plays an essential role in HRV-induced MMP-9 expression. This finding is consistent with earlier reports of NF$\kappa \mathrm{B}-$ dependent MMP-9 expression in response to other stimuli (26). The use of MMP inhibitors in animal models of allergic airway inflammation showed promising results in reducing airway inflammation. By contrast, the use of a broad-spectrum MMP inhibitor in human studies resulted in numerous adverse effects and limited clinical efficacy (41). New approaches, in which individual MMPs specific to the disease or inflammatory condition in question are targeted, offer a way to provide targeted therapy with highly selective inhibitors. Our results indicate that IKK $\beta$ inhibition (during HRV-induced exacerbations) selectively inhibited the increase in MMP-9 expression, thereby maintaining the MMP-9/TIMP-1 ratio at a steady-state level.

Our study has several limitations. The MMP-9 measured in nasal lavage samples did not distinguish between protein generated by airway epithelial cells, and that generated by granulocytes. Neutrophils are a major source of MMP-9 within the airways, and MMP-9 concentrations in airways were found to correlate with neutrophil numbers (42). Infections with HRV are associated with increased neutrophil influx to the airways, and so neutrophils also likely contribute to MMP-9 concentrations in airway secretions. Nonetheless, epithelial cells are the principal site of HRV infection and replication within the airways, and our in vitro data demonstrate that the induction of epithelial MMP-9 is dependent on HRV replication. The strong correlation between MMP-9 concentrations and viral titers in vivo is therefore consistent with a role for epithelial cells as a contributor to MMP-9 concentrations.

In our in vitro experiments, we used both major (HRV-16) and minor (HRV-1A) serotypes, and confirmed that the infection of HBE cells with HRV-1A led to an approximately 10fold greater increase in MMP-9 protein production compared with infection with HRV-16. The reason for this finding is not clear, although the relative expression of the respective cellsurface receptors used by these viruses to gain entry into epithelial cells, and thus the percentage of cells infected, may involve one plausible explanation for the observed differences in MMP-9 expression. Moreover, these two virus serotypes are titered in different cell types, and thus the TCID $_{50}$ used to infect the HBE cells cannot be compared. However, our results do confirm that the increase in MMP-9 expression after infection with both HRV serotypes was dependent on viral replication, because UV-inactivated, replication-deficient HRV did not lead to an increase in MMP-9 mRNA or protein concentrations, compared with uninfected control cells. The role of the NF-кB pathway in HRV-induced MMP-9 expression was demonstrated using pharmacologic IKK $\beta$ inhibitors. However, we acknowledge the limitations of pharmacologic inhibitors with respect to their specificity and possible off-target effects. To verify the specificity of the inhibitors and our results, we used two structurally different, well-studied IKK $\beta$ inhibitors (27).

In conclusion, we have provided robust, novel evidence that the HRV infection of airway epithelial cells significantly and selectively upregulates MMP-9 mRNA and protein concentrations through a mechanism dependent on NF- $\mathrm{B}$, but does not affect TIMP-1 mRNA or protein concentrations.

Author Disclosure: R.N. received consultancy fees from GlaxoSmithKline for $\$ 5,001-\$ 10,000$ as a Review Committee Member, and lectures fees up to
$\$ 1,000$ from both GlaxoSmithKline and AstraZeneca. He has received grants for research funding from GlaxoSmithKline, AstraZeneca, Altana, and Philip Morris, all for more than $\$ 100,001$. R.L. received consultancy fees from GlaxoSmithKline for $\$ 1,001-\$ 5,000$, and has served on the Advisory Board of AstraZeneca, GlaxoSmithKline, and Novartis, receiving \$1,001-\$5,000 from all. $\mathrm{He}$ has received lecture fees from AstraZeneca for $\$ 1,001-\$ 5,000$, from GlaxoSmithKline for $\$ 5,001-10,000$, from Novartis for $\$ 1,001-\$ 5,000$, and from Pfizer for $\$ 1,001-\$ 5,000$. He has also received industry-sponsored grants from Ception for $\$ 10,001-\$ 50,001$, from Medlmmune for $\$ 10,001-\$ 50,001$, and from Novartis for $\$ 1,001-\$ 5,000$, and noncommercial sponsored grants from the Alberta Heritage Foundation for Medical Research and the Canadian Institutes of Health Research, both for $\$ 50,001-\$ 100,000$, and from the Alberta Lung Association for $\$ 10,001-\$ 50,000$. D.P. received consultancy fees from Procter and Gamble for $\$ 1,001-\$ 5,000$, and an industry-sponsored grant from Natural MA, Inc., for $\$ 10,001-\$ 50,000$. C.T. received a studentship from the Alberta Lung Association for $\$ 5,001-\$ 10,000$. None of the other authors have a financial relationship with a commercial entity that has an interest in the subject of this manuscript.

Acknowledgments: The authors thank all the subjects who participated in the clinical study. They also thank Diane Conley, RRT, and Lori Maxwell for technical assistance, and Dr. Wee Yong for assistance with the activity assay.

\section{References}

1. Proud D, Chow CW. Role of viral infections in asthma and chronic obstructive pulmonary disease. Am J Respir Cell Mol Biol 2006;35: 513-518.

2. Mosser AG, Vrtis R, Burchell L, Lee WM, Dick CR, Weisshaar E, Bock D, Swenson CA, Cornwell RD, Meyer KC, et al. Quantitative and qualitative analysis of rhinovirus infection in bronchial tissues. Am J Respir Crit Care Med 2005;171:645-651.

3. Papadopoulos NG, Bates PJ, Bardin PG, Papi A, Leir SH, Fraenkel DJ, Meyer J, Lackie PM, Sanderson G, Holgate ST, et al. Rhinoviruses infect the lower airways. J Infect Dis 2000;181:1875-1884.

4. Rossmann MG. Viral cell recognition and entry. Protein Sci 1994;3: 1712-1725.

5. Proud D. Upper airway viral infections. Pulm Pharmacol Ther 2008;21: 468-473.

6. Leigh R, Oyelusi W, Wiehler S, Koetzler K, Zaheer RS, Newton R, Proud D. Human rhinovirus infection enhances airway epithelial cell production of growth factors involved in airway remodeling. J Allergy Clin Immunol 2008;121:1238-1245.

7. Van den Steen PE, Dubois B, Nelissen I, Rudd PM, Dwek RA, Opdenakker G. Biochemistry and molecular biology of gelatinase B or matrix metalloproteinase-9 (MMP-9). Crit Rev Biochem Mol Biol 2002;37:375-536.

8. Mercer PF, Shute JK, Bhowmik A, Donaldson GC, Wedzicha JA, Warner JA. MMP-9, TIMP-1 and inflammatory cells in sputum from COPD patients during exacerbation. Respir Res 2005;6:151.

9. Lemjabbar H, Gosset P, Lamblin C, Tillie I, Hartmann D, Wallaert B, Tonnel AB, Lafuma C. Contribution of $92 \mathrm{kDa}$ gelatinase/type IV collagenase in bronchial inflammation during status asthmaticus. Am J Respir Crit Care Med 1999;159:1298-1307.

10. Tacon CE, Wiehler S, Proud D, Leigh R. Rhinovirus infection of the airway epithelium regulates matrix metalloproteinase production: a potential mechanism in the pathogenesis of airway remodeling. Am J Respir Crit Care Med 2008;177:A728.

11. Tacon CE, Wiehler S, Newton R, Proud D, Leigh R. Human rhinovirus increases MMP-9 expression in vitro and in vivo. Am J Respir Crit Care Med 2009;179:A5146.

12. Gern JE, Vrtis R, Kelly EA, Dick EC, Busse WW. Rhinovirus produces nonspecific activation of lymphocytes through a monocyte-dependent mechanism. J Immunol 1996;157:1605-1612.

13. Sanders SP, Siekierski ES, Porter JD, Richards SM, Proud D. Nitric oxide inhibits rhinovirus-induced cytokine production and viral replication in a human respiratory epithelial cell line. J Virol 1998; 72:934-942.

14. Churchill L, Chilton FH, Resau JH, Bascom R, Hubbard WC, Proud D. Cyclooxygenase metabolism of endogenous arachidonic acid by cultured human tracheal epithelial cells. Am Rev Respir Dis 1989; 140:449-459.

15. Mosser AG, Brockman-Schneider R, Amineva S, Burchell L, Sedgwick JB, Busse WW, Gern JE. Similar frequency of rhinovirus-infectible cells in upper and lower airway epithelium. J Infect Dis 2002;185: 734-743.

16. Sanders SP, Siekierski ES, Richards SM, Porter JD, Imani F, Proud D. Rhinovirus infection induces expression of type 2 nitric oxide 
synthase in human respiratory epithelial cells in vitro and in vivo. $J$ Allergy Clin Immunol 2001;107:235-243.

17. Gum R, Lengyel E, Juarez J, Chen JH, Sato H, Seiki M, Boyd D. Stimulation of $92-\mathrm{kDa}$ gelatinase $\mathrm{B}$ promoter activity by ras is mitogen-activated protein kinase kinase 1-independent and requires multiple transcription factor binding sites including closely spaced PEA3/ets and AP-1 sequences. $J$ Biol Chem 1996;271:10672-10680.

18. Song Y, Qian L, Song S, Chen L, Zhang Y, Yuan G, Zhang H, Xia Q, $\mathrm{Hu} \mathrm{M}, \mathrm{Yu} \mathrm{M}$, et al. Fra-1 and Stat3 synergistically regulate activation of human MMP-9 gene. Mol Immunol 2008;45:137-143.

19. Westermarck J, Kahari VM. Regulation of matrix metalloproteinase expression in tumor invasion. FASEB J 1999;13:781-792.

20. Koetzler R, Zaheer RS, Wiehler S, Holden NS, Giembycz MA, Proud D. Nitric oxide inhibits human rhinovirus-induced transcriptional activation of CXCL10 in airway epithelial cells. J Allergy Clin Immunol 2009;123:201-208.

21. Sanders SP, Proud D, Permutt S, Siekierski ES, Yachechko R, Liu MC Role of nasal nitric oxide in the resolution of experimental rhinovirus infection. J Allergy Clin Immunol 2004;113:697-702.

22. Wang X, Lau C, Wiehler S, Pow A, Mazzulli T, Gutierrez C, Proud D, Chow CW. Syk is downstream of intercellular adhesion molecule-1 and mediates human rhinovirus activation of p38 MAPK in airway epithelial cells. J Immunol 2006;177:6859-6870.

23. Lau C, Wang X, Song L, North M, Wiehler S, Proud D, Chow CW. Syk associates with clathrin and mediates phosphatidylinositol 3-kinase activation during human rhinovirus internalization. J Immunol 2008; 180:870-880

24. Van Wart HE, Birkedal-Hansen H. The cysteine switch: a principle of regulation of metalloproteinase activity with potential applicability to the entire matrix metalloproteinase gene family. Proc Natl Acad Sci USA 1990;87:5578-5582.

25. Kim J, Sanders SP, Siekierski ES, Casolaro V, Proud D. Role of NFkappa B in cytokine production induced from human airway epithelial cells by rhinovirus infection. J Immunol 2000;165:3384-3392.

26. Yan C, Boyd DD. Regulation of matrix metalloproteinase gene expression. J Cell Physiol 2007;211:19-26.

27. Bain J, Plater L, Elliott M, Shpiro N, Hastie CJ, McLauchlan H, Klevernic I, Arthur JS, Alessi DR, Cohen P. The selectivity of protein kinase inhibitors: a further update. Biochem J 2007;408:297-315.

28. Newton R, Holden NS, Catley MC, Oyelusi W, Leigh R, Proud D, Barnes PJ. Repression of inflammatory gene expression in human pulmonary epithelial cells by small-molecule IkappaB kinase inhibitors. J Pharmacol Exp Ther 2007;321:734-742.

29. Chandrasekar B, Mummidi S, Mahimainathan L, Patel DN, Bailey SR, Imam SZ, Greene WC, Valente AJ. Interleukin-18-induced human coronary artery smooth muscle cell migration is dependent on NFkappaB- and AP-1-mediated matrix metalloproteinase-9 expression and is inhibited by atorvastatin. J Biol Chem 2006;281:15099-15109.
30. Ogawa K, Chen F, Kuang C, Chen Y. Suppression of matrix metalloproteinase- 9 transcription by transforming growth factor-beta is mediated by a nuclear factor-kappaB site. Biochem $J$ 2004;381: $413-422$.

31. He C. Molecular mechanism of transcriptional activation of human gelatinase B by proximal promoter. Cancer Lett 1996;106: 185-191.

32. Wang JH, Kwon HJ, Jang YJ. Rhinovirus upregulates matrix metalloproteinase-2, matrix metalloproteinase-9, and vascular endothelial growth factor expression in nasal polyp fibroblasts. Laryngoscope 2009;119:1834-1838.

33. Ra HJ, Parks WC. Control of matrix metalloproteinase catalytic activity. Matrix Biol 2007;26:587-596.

34. Cataldo DD, Tournoy KG, Vermaelen K, Munaut C, Foidart JM, Louis R, Noel A, Pauwels RA. Matrix metalloproteinase-9 deficiency impairs cellular infiltration and bronchial hyperresponsiveness during allergen-induced airway inflammation. Am J Pathol 2002;161:491498.

35. Kumagai K, Ohno I, Okada S, Ohkawara Y, Suzuki K, Shinya T, Nagase $\mathrm{H}$, Iwata K, Shirato K. Inhibition of matrix metalloproteinases prevents allergen-induced airway inflammation in a murine model of asthma. J Immunol 1999;162:4212-4219.

36. McMillan SJ, Kearley J, Campbell JD, Zhu XW, Larbi KY, Shipley JM, Senior RM, Nourshargh S, Lloyd CM. Matrix metalloproteinase-9 deficiency results in enhanced allergen-induced airway inflammation. J Immunol 2004;172:2586-2594.

37. Corry DB, Kiss A, Song LZ, Song L, Xu J, Lee SH, Werb Z, Kheradmand F. Overlapping and independent contributions of MMP2 and MMP9 to lung allergic inflammatory cell egression through decreased CC chemokines. FASEB J 2004;18:995-997.

38. Castaneda FE, Walia B, Vijay-Kumar M, Patel NR, Roser S, Kolachala VL, Rojas M, Wang L, Oprea G, Garg P, et al. Targeted deletion of metalloproteinase 9 attenuates experimental colitis in mice: central role of epithelial-derived MMP. Gastroenterology 2005;129:19912008.

39. Vignola AM, Paganin F, Capieu L, Scichilone N, Bellia M, Maakel L, Bellia V, Godard P, Bousquet J, Chanez P. Airway remodelling assessed by sputum and high-resolution computed tomography in asthma and COPD. Eur Respir J 2004;24:910-917.

40. Malavia NK, Raub CB, Mahon SB, Brenner M, Panettieri RA Jr, George SC. Airway epithelium stimulates smooth muscle proliferation. Am J Respir Cell Mol Biol 2009;41:297-304.

41. Hu J, Van den Steen PE, Sang QX, Opdenakker G. Matrix metalloproteinase inhibitors as therapy for inflammatory and vascular diseases. Nat Rev Drug Discov 2007;6:480-498.

42. Cundall M, Sun Y, Miranda C, Trudeau JB, Barnes S, Wenzel SE. Neutrophil-derived matrix metalloproteinase- 9 is increased in severe asthma and poorly inhibited by glucocorticoids. J Allergy Clin Immunol 2003;112:1064-1071. 